\title{
The Geo-Information System Application for Display of the Tsunami Type Long Wave Propagation Modeling Results in the Black Sea Coastal Area
}

\author{
A.Yu. Basykina*, E.V. Zhuk, A.Kh. Khaliulin \\ Marine Hydrophysical Institute RAS, Sevastopol, Russian Federation \\ *e-mail: aleksa.44.33@gmail.com
}

\begin{abstract}
Study of the tsunami wave propagation in the coastal zone is an important practical task in the field of oceanology. Although tsunami in the Black Sea is a rare phenomenon, however, the level of seismic activity in the region does not permit to exclude generation of strong tsunami waves due to the underwater earthquakes. The computation experiments make it possible to analyze the features of the tsunami type wave transformation and to determine the sea level changes in the coastal zone. The geo-information system is shown to be is applied to visualize the tsunami type long wave propagation modeling results in the Black Sea coastal area. Within the framework of the nonlinear long wave theory, the Propagation of Surface Long Tsunami Type Waves in the Black Sea Coastal Zone software model is developed. It is integrated into the Black Sea geo-information system. The software module providing data exchange between the geo-information system and the model is developed. It permits to analyze the wave field transformation features and to quantify the wave amplitude characteristics when they propagate towards different sections of the Black Sea coast.

The results of the software module operation are represented based on the example of the Feodosiya Gulf. The instantaneous fields of sea level displacements in the gulf and the horizontal velocity fields are constructed. The values of the sea level maximum elevation and sink in the basin are calculated. The mareograms in the specified zones which allow the assessment of tsunami risk for the Feodosiya Gulf coast are also constructed.
\end{abstract}

Keywords: geo-information system, tsunami type waves, nonlinear long wave propagation, waves in gulfs and bays, tsunami risk for the Black Sea coast.

DOI: 10.22449/1573-160X-2017-3-69-76

(C) 2017, A.Yu. Basykina, E.V. Zhuk, A.Kh. Khaliulin

(C) 2017, Physical Oceanography

\section{Introduction}

The sea coast is always exposed to intense wave action. The coastline and bottom topography nature affects the propagation of long waves in coastal zones of the marine basins [1]. Inhomogeneity of the depth and shoreline geometric parameters can lead to a significant amplification of the waves. The issue of how the edge effects caused by the geometry of the coastline of an arbitrary shape and the bottom topography affect the long wave field formation near the shore needs to be investigated.

Tsunami type waves are surface gravitational long waves that occur in the sea due to large-scale disturbances such as earthquakes, eruptions of underwater volcanoes, landslides, abrupt changes in meteorological conditions, etc. Tsunami waves are quite rare in the Black Sea: about 20 events have been noted in this region for the last two thousand years [2, 3]. Historical descriptions show that the tsunami waves that occurred in Sukhumi (AD 20), Chersonesos (Sevastopol) (AD 103), Varna (AD 543), the Bosporus (AD 557) ), Evpatoria (1341), Foros (1427), in the north of Turkey (1598), were catastrophic. The sea level elevation height reached 2-3 m, which led to heavy floods and destruction [4]. 
This phenomenon can take place anywhere on the coast. It is caused both by underwater and land earthquakes.

When a long tsunami wave propagates in shallow water, its front slope slows down, and the back one moves faster. The shape of the wave is transformed: the crest becomes higher, and the hollow is deeper. As a result, the front slope of the wave becomes steeper, the crest begins to crash forward, and, splashing on the shore, the wave produces heavy damage.

The study and analysis of the features of tsunami wave propagation and their timely forecast can prevent the death of people and reduce the material damage. Under the guidance of Sergey Dotsenko the numerical simulation of tsunami wave propagation in the Black coastal zone Sea [5-9] were carried out. Such models need reliable information support, the geo-information systems (GIS) are created for. They help to computerize the processes of obtained data processing and presentation. A set of software was developed. It permits to digitize the mareograms, to estimate the frequency spectra, to select the energy-carrying vibrations and calculate the tsunami propagation and duration time for various coastal points [10]. The idea of integration of the models into GIS, which evaluates the evolution of waves and their amplitude characteristics, is also worth considering. Similar systems are discussed in $[11,12]$.

At the moment, Marine Environmental \& Information Technologies Department of FSBSI Marine Hydrophysical Institute RAS is developing such information systems [13, 14] applying the Mapserver [15]. To provide users with a special tool for rapid response, the software modules have been created. They permit to visualize the results of work conducted under the guidance of Sergey Dotsenko (numerical simulation of the propagation of nonlinear long tsunami type waves in the sea coastal zone, in bays and gulfs). These modules allow displaying the evolution of waves as they propagate in shallow water and in the coastal zone, and also to quantify their amplitude features. Thus, it becomes possible for the user to quickly predict possible danger in the area of interest of the Black Sea coast due to the exposure of long tsunami waves.

\section{Description of the Propagation of Surface Long Tsunami Type Waves in the Black Sea Coastal Zone software model}

In the horizontal plane Oxy ( $x$ and $y$ are the Cartesian coordinates of the point on the plane), a bay with depth $h=h(x, y)$, varying continuously according to a known law, is considered.

To describe the surface long wave propagation, a nonlinear long-wave model is applied. It operates with projections of the horizontal velocities averaged over the depth $u=u(x, y, t), v=v(x, y, t)$, where $t$ is the time, and the free surface displacement of the liquid $\zeta=\zeta(x, y, t)$. 
Within the framework of this approach, the nonlinear dynamics of long waves in the two-dimensional case taking into account the quadratic bottom friction is described by the following system of three equations

$$
\begin{gathered}
\frac{\partial u}{\partial t}+u \frac{\partial u}{\partial x}+v \frac{\partial u}{\partial y}+g \frac{\partial \zeta}{\partial x}=-k \frac{u \sqrt{u^{2}+v^{2}}}{(h+\zeta)}, \\
\frac{\partial v}{\partial t}+u \frac{\partial v}{\partial x}+v \frac{\partial v}{\partial y}+g \frac{\partial \zeta}{\partial y}=-k \frac{v \sqrt{u^{2}+v^{2}}}{(h+\zeta)}, \\
\frac{\partial \zeta}{\partial t}+\frac{\partial[(h+\zeta) u]}{\partial x}+\frac{\partial[(h+\zeta) v]}{\partial y}=0,
\end{gathered}
$$

where $g$ is the free fall acceleration; $k=2.6 \cdot 10^{-3}$ is the quadratic bottom friction coefficient.

The initial conditions for the system of equations (1) require the fields $u, v$ and $\zeta$ to be set at the initial instant $t=0$. We assume that under $t=0$ the liquid in the bay is in an unperturbed state, i.e.

$$
u(x, y, 0)=v(x, y, 0)=\zeta(x, y, 0)=0 .
$$

Through an open boundary ( $0 \leq x \leq L, y=0$, $\mathrm{L}$ is the liquid boundary length), a flat wave of a half-sinusoid shape, simulated by the following boundary conditions, enters the bay

$$
\begin{gathered}
\zeta=a_{0} \sin \left(\frac{\pi C t}{\lambda}\right), \\
v=\frac{g}{C} \zeta \quad\left(0 \leq x \leq L, y=0,0 \leq t \leq \frac{\lambda}{C}\right), \\
C=\sqrt{g h},
\end{gathered}
$$

where $a_{0}$ is the maximum initial displacement of the free surface of the liquid; $\lambda$ is the initial wavelength; $C=C(x, 0)$ is the local propagation velocity of linear long waves.

On the liquid sections of the boundary the conditions for the free escape of linear long waves from the computational domain are set

$$
\begin{array}{ll}
\frac{\partial v}{\partial t}-C_{1} \frac{\partial v}{\partial x}=0 & \left(0 \leq y \leq M_{1}, x=0, t>0\right), \\
\frac{\partial v}{\partial t}+C_{n} \frac{\partial v}{\partial x}=0 & \left(0 \leq y \leq M_{n}, x=L, t>0\right),
\end{array}
$$


where $C_{1}$ and $C_{n}$ are the local propagation velocities of linear long waves along $x$ $=0$ and $x=L$, respectively; $M_{1}$ and $M_{n}$ is the length of the liquid boundaries along $x=0$ and $x=L$.

At the liquid boundary the wave $(y=0)$ enters through, the condition for free wave exit is applied only after the wave enters the bay completely:

$$
\frac{\partial u}{\partial t}-C \frac{\partial u}{\partial x}=0(0 \leq x \leq L, y=0, t \geq \lambda / C) .
$$

On solid sections of the shore boundaries, the no-liquid-loss conditions along the $y$ and $x$ axes respectively were set

$$
\mathbf{v}_{n}=0,
$$

where $\mathbf{v}_{n}$ is the projection of the horizontal liquid velocity normal to the boundary of the region.

The initial boundary value problem (1) - (9) is solved numerically by the finite difference method in an explicitly implicit scheme. For displacements of the free surface of the liquid $\zeta$ and the projections of the horizontal velocities $u$ and $v$, the spaced grids (Arakawa $C$ grid) are used. The steps of integration over space and time are calculated from the Courant condition.

Possibilities of the program developed allow investigating the propagation of nonlinear long tsunami type waves in the coastal zone of real and model geometry. An array of distribution of the investigated zone depths is set at the input. At the output the data for evaluation of the evolution and transformation of long tsunami type waves in a given water area is obtained. Thus, the primary focus in the problem solution is given to the features of the tsunami type wave propagation and the distribution of amplitude wave characteristics in the coastal zone.

As an example, single long tsunami type wave propagation in the Feodosiya Gulf of the Black Sea is considered [8]. The Feodosiya Gulf is located on the south-eastern coast of the Crimea. The gulf size is $20 \mathrm{~km}$ latitudinally and $40 \mathrm{~km}$ longitudinally. The depth at the entrance is $30-35 \mathrm{~m}$. The Feodosiya Gulf is characterized by an even flat bottom (Fig. 1).

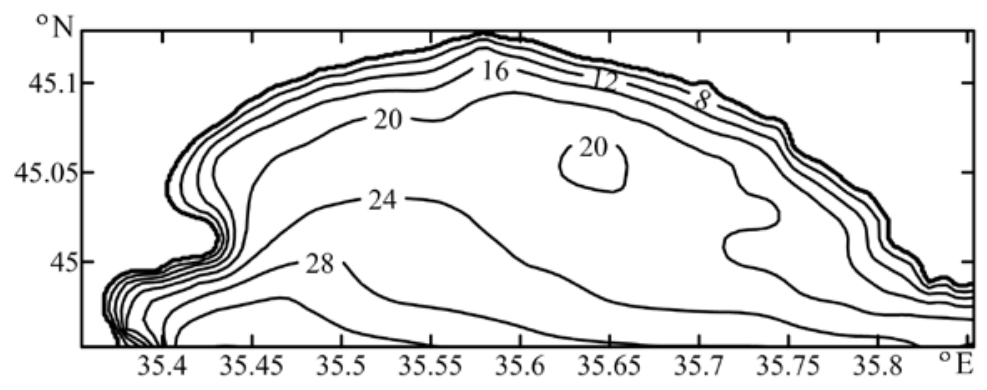

Fig. 1. The Feodosiya Gulf bathymetry 
An array of depths and the number of grid points by longitude and latitude ( $n x$ and ny, respectively) are set at the input. For an array describing the Feodosiya Bay bottom topography $-n x=389$, $n y=196$. The computational grid is uniform, with space steps $\Delta x=\Delta y=100 \mathrm{~m}$, which is 0.00125 longitudinally and 0.0009009 latitudinally. The time step was set to $1 \mathrm{~s}$. The approximate velocity of wave propagation is estimated from the formula (5).

To integrate the Propagation of Surface Long Tsunami Type Waves in the Black Sea Coastal Zone software model in the Black Sea GIS, a software module was developed. It provides data exchange between the GIS and the model, as well as launches the model.

Before launching the software module, the boundary coordinates of the computational area should be specified and the initial parameters of the wave to be set (Fig. 2). As an example, the following values were given: the initial height of the long wave entering in the Feodosiya Gulf, height $=1 \mathrm{~m}$, the initial wavelength length $=10 \mathrm{~km}$. Output time interval $=10 \mathrm{~s}$ shows the interval at which it is necessary to derive instantaneous distributions of wave amplitude characteristics in the simulation region.

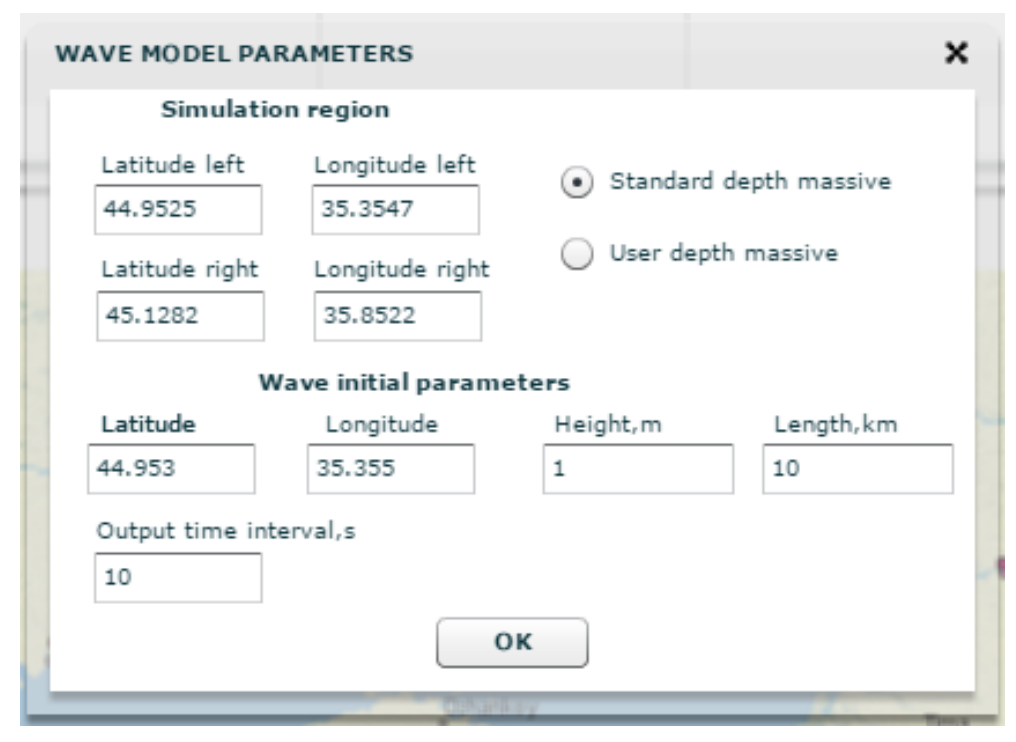

Fig. 2. Parameter input interface of the Propagation of Surface Long Tsunami Type Waves in the Black Sea Coastal Zone software model

At the output we obtain the sea level fields in the simulation region and the projections of the horizontal velocities longitudinally and latitudinally with a given time interval. 
GIS permits to give a visual presentation of the data. Fig. 3 shows the distribution of sea level and the velocity vector field in the Feodosiya Gulf at the time point $t=2030 \mathrm{~s}$.

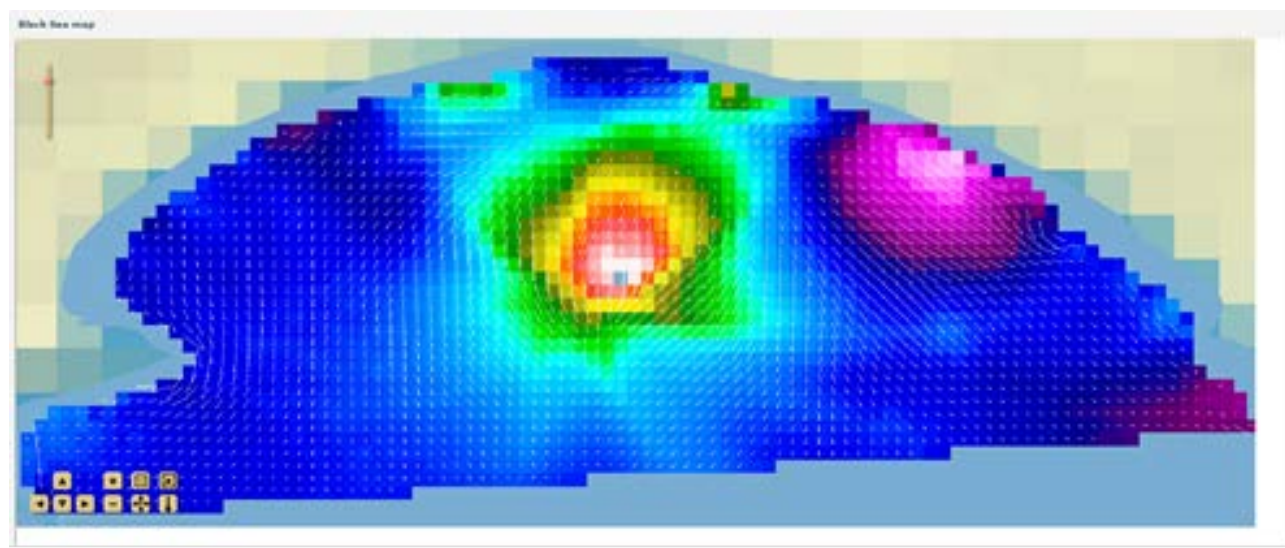

Fig. 3. Distribution of sea level and the velocity vector field at the time point $t=2030 \mathrm{~s}$ under the nonlinear long wave propagation in the Feodosiya Gulf (with the initial wave parameters $a 0=1 \mathrm{~m}$, $\lambda=10 \mathrm{~km})$

In addition to the data described above, the values of the maximum and minimum wave height change in the Gulf over time, with reference to longitude and latitude are obtained. Fig. 4 shows the dependence of the maximum wave height in the gulf on the time.

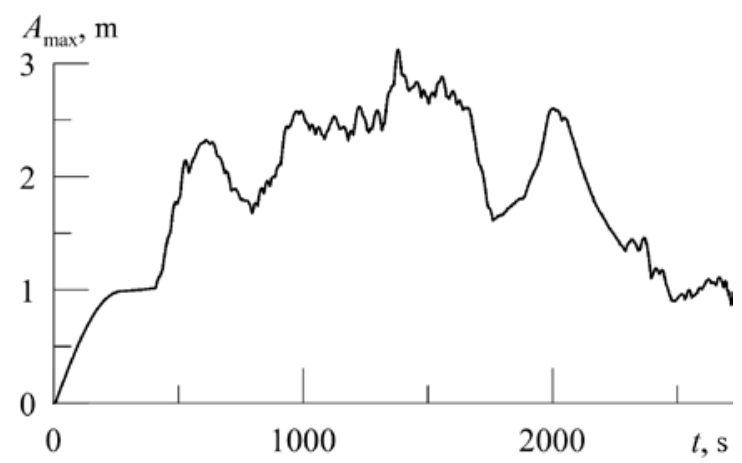

Fig. 4. Distribution of the maximum sea level height over time under a single nonlinear long wave propagation in the Feodosiya Gulf (with the initial wave parameters $a_{0}=1 \mathrm{~m}, \lambda=10 \mathrm{~km}$ )

Having visually evaluated the extreme sea level displacements and determined their coordinate dimensioning, the user can obtain the mareograms in those zones of the simulation region that appear to be the most dangerous. For example, two local maxima in Fig. 4, indicating the wave amplification at time points 1380 and 2000 s, are singled out. Fig. 5 shows the mareograms of the wave amplification zones in the Feodosiya Gulf. It can be seen that in these areas there are both sea level rise and extreme depressions. 


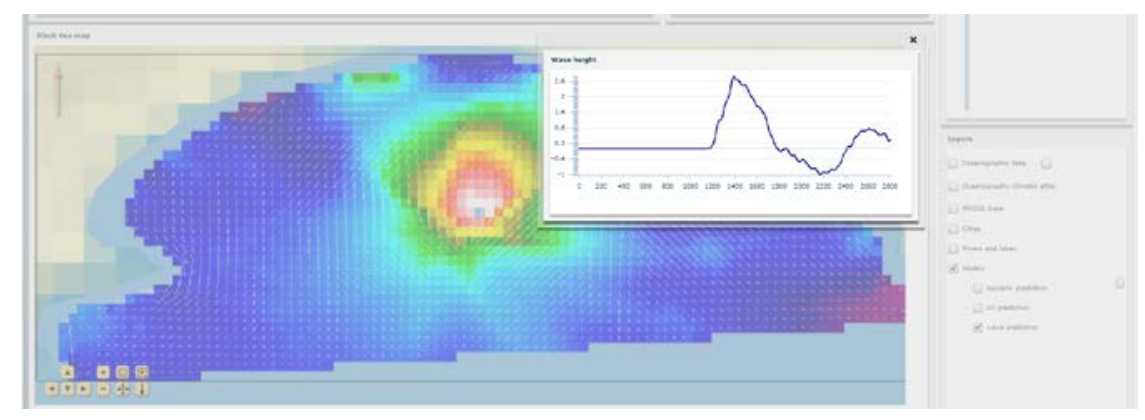

$a$

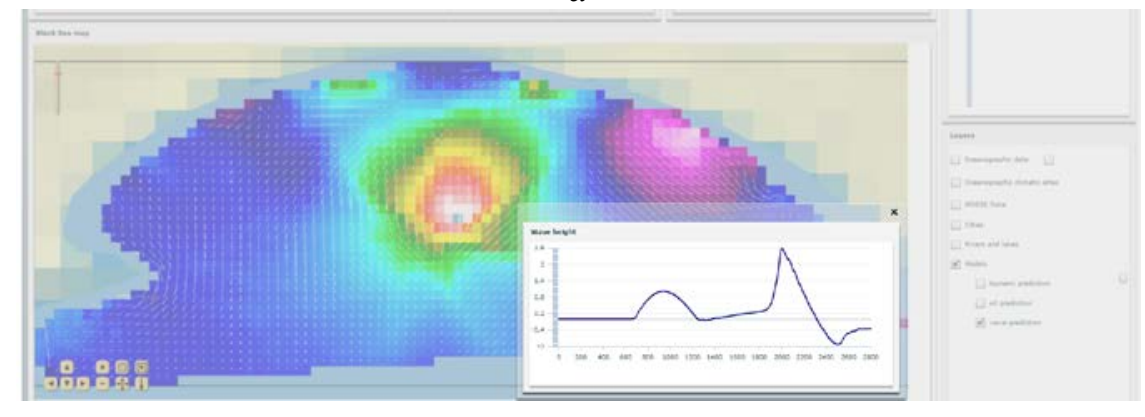

$b$

Fig. 5. The mareograms of the wave amplification zones in the Feodosiya Gulf: $a-45,05^{\circ} \mathrm{N}$, $35,59^{\circ} \mathrm{E} ; b-45,10^{\circ} \mathrm{N}, 35,69^{\circ} \mathrm{E}$

\section{Conclusions}

The special software modules built in the Black Sea GIS allow qualitative solution of the problems of long tsunami wave simulation in the interface of land and sea, providing a quantitative assessment of their amplitude characteristics under the propagation of waves in shallow water and in the coastal zone, and also provide an intuitive interface and visualization of the simulation results.

\section{REFERENCES}

1. Kononkova, G.E. and Pokazeev, K.V., 1985. Dinamika Morskikh Voln [Dynamics of Sea Waves]. Moscow: MGU Publ., 298 p. (in Russian).

2. Nikonov, A.A., 1997. Tsunami na Beregakh Chernogo i Azovskogo Morey [Tsunami on the Shores of the Black and Azov Seas]. Izvestiya. Physics of the Solid Earth, 33(100), pp. 86-96 (in Russian).

3. Solov'eva, O.N., Dotsenko, S.F., Kuzin, I.P. and Levin, B.V., 2004. Tsunami in the Black Sea: Historical Events, Seismic Sources, and Features of Propagation. Oceanology, 44(5), pp. 638-643.

4. Dotsenko, S.F. and Ivanov, V.A., 2010. Prirodnye Katastrofy Azovo-Chernomorskogo Regiona [The Azov-Black Sea Region Nature Catastrophes]. Sevastopol: ECOSI-Gidrofizika, 174 p. (in Russian).

5. Dotsenko, S.F. and Ingerov, A.V., 2010. Numerical Analysis of the Propagation and Amplification of Tsunami Waves on the Northwest Shelf of the Black Sea. Physical Oceanography, [e-journal] 20(5), pp. 325-334. doi:10.1007/s11110-011-9088-4

6. Dotsenko, S.F. and Ingerov, A.V., 2010. Numerical Modeling of the Propagation and Strengthening of Tsunami Waves near the Crimean Peninsula and the Northeast Coast of the Black Sea. Physical Oceanography, [e-journal] 20(1), pp. 1-13. doi:10.1007/s11110-0109063-5 
7. Dotsenko, S.F. and Ingerov, A.V., 2013. Kharakteristika Voln Tsunami Seysmicheskogo Proiskhozhdeniya v Basseyne Chernogo Morya po Rezul'tatam Chislennogo Modelirovaniya [Characteristics of Tsunami Waves of Seismic Origin in the Black Sea Basin according to Numerical Simulation Results]. Morskoy Gidrofizicheskiy Zhurnal, (3), pp. 25-34 (in Russian).

8. Bazykina, A.Yu. and Dotsenko, S.F., 2016. Propagation of Tsunami-Like Surface Long Waves in the Bays of a Variable Depth. Physical Oceanography, [e-journal] (4), pp. 3-12. doi:10.22449/1573-160X-2016-4-3-11

9. Bazykina, A.Yu., Dotsenko, S.F. and Ingerov, A.V., 2016. Osobennosti Rasprostraneniya Voln Tipa Tsunami v Pribrezhnoy Zone Chernogo Morya [Features of Tsunami Wave Propagation in the Black Sea Coastal Zone]. In: Tezisy Dokladov Nauchnoy Konferentsii "Mirovoy Okean: Modeli, Dannye i Operativnaya Okeanologiya" [Summaries of the Scientific Conference "World Ocean: Models, Data and Operational Oceanography”. 26-30 September 2016, Sevastopol]. Sevastopol: FGBUN MGI, pp. 47-48 (in Russian).

10. Belokopytov, V.N., Khaliulin, A.Kh., Godin, E.A, Konovalov, S.K., Dotsenko, S.F., Ingerov, A.V., Sergeeva, A.V. and Gorbunov, V.P., 2012. Programmnoe Obespechenie Dlya Morskikh Ekologicheskikh Issledovaniy [Software for Marine Environmental Research]. In: MHI, 2012. Ustoychivost' i Evolyutsiya Okeanologicheskikh Kharakteristik Ekosistemy Chernogo Morya [Stability and Evolution of the Oceanological Characteristics of the Black Sea Ecosystem]. Sevastopol: ECOSI-Gidrofizika, pp. 32-42 (in Russian).

11. Wijesundara, W.A.A.P., 2014. GIS Based Tsunami Risk Assessment in Weligma, Sri Lanka. Universal J. Geosci., [e-journal] 2(8), pp. 242-250. doi:10.13189/ujg.2014.020802

12. Mathur Dhruvesh, K. and Udani Praful., M., 2015. Tsunami Detection and Assessment Using Remote Sensing and GIS. Int. J. Eng. Res. Gen. Sci., [e-journal] 3(6), pp. 810-817. Available at: http://oaji.net/articles/2015/786-1451214155.pdf [Accessed 15 December 2016].

13. Zhuk, E.V., Godin, E.A., Ingerov, A.V. and Khaliulin, A.Kh., 2016. Opyt Razrabotki GIS Chernogo Morya na Osnove Besplatnogo Programmnogo Obespecheniya [Experience in Developing the Black Sea GIS on the Basis of Open Software]. Geoprofi, (2), pp. 36-40 (in Russian).

14. Zhuk, E., Khaliulin, A., Zodiatis, G., Nikolaidis, A. and Isaeva, E., 2016. Black Sea GIS developed in MHI. In: Proc. SPIE 9688. Fourth Intern. Conf. on Remote Sensing and Geoinform. of the Environment (RSCy2016). August 12, 2016. Paphos, Cyprus, 2016. 96881C. doi:10.1117/12.2241631

15. MapServer. 2017. Open Source Web Mapping. [online] Available at: http://mapserver.org. [Accessed 6 January 2017]. 